\title{
Correction: A semi-analytical solution for groundwater flow-field delineation near pumping/injection wells in confined aquifers
}

\section{loan Bica ${ }^{1} \cdot$ Mohamed Amine Boukhemacha $^{2}$ (D) Ghiocel Groza $^{3}$}

Published online: 1 February 2020

(C) Springer-Verlag GmbH Germany, part of Springer Nature 2020

\section{Correction: Hydrogeology Journal (2019) 27:61-71}

https://doi.org/10.1007/s10040-018-1869-0

The original version of this article unfortunately contained a misprint. Equation 8 was written incorrectly. The correct form of this equation is as follows:

$$
\left\{\begin{array}{l}
A_{1, k}=G_{k}[x(t), y(t)] \\
A_{2, k}=G_{k}\left[x(t)+\frac{\Delta t}{2} A_{1,1}, y(t)+\frac{\Delta t}{2} A_{1,2}\right] \\
A_{3, k}=G_{k}\left[x(t)+\frac{\Delta t}{2} A_{2,1}, y(t)+\frac{\Delta t}{2} A_{2,2}\right] \\
A_{4, k}=G_{k}\left[x(t)+\Delta t \cdot A_{3,1}, y(t)+\Delta t \cdot A_{3,2}\right]
\end{array}\right.
$$

All computations presented in this article were made using the correct form of eq. 8 and are not affected by this misprint.

The online version of the original article can be found at https://doi.org/ 10.1007/s10040-018-1869-0

Mohamed Amine Boukhemacha

boukhemacha-amine@hotmail.com

Ioan Bica

ioan.bica@utcb.ro

Ghiocel Groza

grozag@utcb.ro

1 Department of Hydraulics and Environment Protection, Technical University of Civil Engineering Bucharest, Bd. Lacul Tei nr. 122 124, 020396, sector 2, Bucharest, Romania

2 Department of Hydraulics, National Polytechnic School, 10 Avenue Hassen Badi BP 182 El-Harrach, 16200 Algiers, Algeria

3 Department of Mathematics and Computer Science, Technical University of Civil Engineering Bucharest, Bd. Lacul Tei nr. 122 124, 020396, sector 2, Bucharest, Romania 